\title{
Erratum: Analogous intruder behavior near Ni, Sn, and Pb isotopes [Phys. Rev. C 92, 024319 (2015)]
}

S. N. Liddick, W. B. Walters, C. J. Chiara, R. V. F. Janssens, B. Abromeit, A. Ayres, A. Bey, C. R. Bingham, M. P. Carpenter, L. Cartegni, J. Chen, H. L. Crawford, I. G. Darby, R. Grzywacz, J. Harker, C. R. Hoffman, S. Ilyushkin, F. G. Kondev, N. Larson, M. Madurga, D. Miller, S. Padgett, S. V. Paulauskas, M. M. Rajabali, K. Rykaczewski, D. Seweryniak, S. Suchyta, and S. Zhu

(Received 18 November 2016; published 30 December 2016)

DOI: 10.1103/PhysRevC.94.069904

In the interpretation of neutron knockout reactions leading to ${ }^{69} \mathrm{Ni}[1]$, a transcription error was discovered in the third column of Table I in the original paper, reporting the absolute $\gamma$-ray intensities of transitions in ${ }^{69} \mathrm{Ni}$. The corrected table is provided here as Table I. This correction does not affect any of the conclusions presented in the original paper.

TABLE I. $\gamma$-ray energies and absolute intensities following the decay of ${ }^{69} \mathrm{Co}$ from the present paper compared to previous literature values.

\begin{tabular}{lccr}
\hline \hline & Present paper fragmentation & Present paper $\beta$ decay & Ref. [2] \\
\hline$E(\mathrm{keV})$ & Intensity (\%) & Intensity $(\%)$ & Intensity $(\%)$ \\
\hline $594.2(4)$ & $42(4)$ & $29(3)$ & $56.7(47)$ \\
$602.4(4)$ & $4.4(12)$ & $2.4(7)$ & $8.9(12)$ \\
$1128.5(5)$ & $2.6(11)$ & $2.5(7)$ & $8.3(13)$ \\
$1196.3(4)$ & $9.0(20)$ & $7.4(10)$ & $11.2(16)$ \\
$1319(1)$ & $0.6(3)$ & $4.1(9)$ & $9.2(14)$ \\
\hline \hline
\end{tabular}

[1] F. Recchia et al., Phys. Rev. C 94, 054324 (2016).

[2] W. F. Mueller, B. Bruyneel, S. Franchoo, H. Grawe, M. Huyse, U. Köster, K.-L. Kratz, K. Kruglov, Y. Kudryavtsev, B. Pfeiffer, R. Raabe, I. Reusen, P. Thirolf, P. Van Duppen, J. Van Roosbroeck, L. Vermeeren, W. B. Walters, and L. Weissman, Phys. Rev. Lett. 83, 3613 (1999). 